\title{
Knowledge and View of Mothers Whose Babies in Newborn Intensive Care Units About Breast Milk Banking in Turkey
}

\author{
Reyyan Gürel' (D, Ayten Șentürk Erenel ${ }^{(1)}$ \\ 'Bașkent Universty Faculty of Health Sciences, Ankara, Turkey \\ ${ }^{2}$ Gazi University Faculty of Health Sciences, Ankara, Turkey
}

ORCID IDs of the authors: R.G. 0000-0003-I2I7-I002; A.Ș.E. 0000-0002-084I-2099.

Cite this article as: Gürel R, Erenel Șentürk A. Knowledge and View of Mothers Whose Babies in Newborn Intensive Care Units About Breast Milk Banking in Turkey. Cyprus J Med Sci 2020; 5(I): 5I-6.

\section{BACKGROUND/AIMS}

This study aimed to assess the knowledge, awareness, and attitudes of mothers whose babies were in the newborn intensive care units about breast milk banking.

\section{MATERIALS and METHODS}

The participants of this descriptive research were 102 mothers who provided their oral and written consent for study participation and whose newborns were in the intensive care units during June to August 2016 ( $n=102$ ). A p value $<0.05$ was considered to indicate statistical significance.

\section{RESULTS}

We found a statistically significant relationship of the "Request to Benefit from Breast Milk Banking" with the educational background, working status, and the place where the mothers had spent most of their lives. In addition, there was a statistically significant relationship of the "Request to Donate Breast Milk to the Breast Milk Banks" with the place where the mothers had spent most of their lives, breastfeeding experience, and the institution from which they had received care before the delivery $(p<0.05)$.

\section{CONCLUSION}

Although a considerable proportion of the mothers have positive thoughts about breast milk banking, they were hesitant about feeding their babies donor milk when needed.

Keywords: Breastfeeding, human milk banking, milk banking, Turkey.

\section{INTRODUCTION}

Feeding newborns with breast milk is a fundamental element of healthy growth and development (I, 2). The World Health Organization (WHO) and many international organizations recommend that infants should be fed only breast milk for the first 6 months; thereafter, liquid and solid supplements should be started. Furthermore, it is also recommended that breast-feeding be continued until the baby gives it up $(1,3)$. In addition to being the optimum exclusive source of nutrition for the infants, breast milk provides several benefits to human health both in the early years and beyond (I). Therefore, the United Nations International Children's Emergency Fund (UNICEF), the WHO, and many international health organizations emphasize the importance of breast milk for newborns $(1,3)$. The UNICEF has stated that the practice of breast-feeding can save the lives of approximately 1.5 million infants annually (4). Thus, it has been pointed out that it is the human right of each infant to be fed breast milk to allow the achievement of optimal health. Studies have shown that breast-feeding is crucial for infants who are treated in newborn intensive care units for various reasons, and the most suitable approach involves the use of donor milk in situations where the infant cannot be fed its own mother's milk $(3,5,6)$.

Breast milk banks are the most suitable and important source of breast milk for babies who cannot be fed its own mother's milk for various reasons (7). Donor milk undergoes a rigorous health-screening process. Breast milk banks are institutions that provide breast milk to infants who need it by sourcing it from mothers who produce more milk than that needed 
by their own children or from those who donate their milk for some other reasons, such as death of their own child. Donor milk is subjected to pasteurization and a health-screening process. Milk banking first began in the 1900s in Boston and continues to function in many countries of the world (8). In Turkey, several initiatives have been undertaken to establish a breast milk bank; however, there has not been any milk banks in Turkey. In addition, when the literature regarding this subject is examined, few studies were found that involved both healthcare personnel and the general public; thus, limited information is available regarding this subject (9). Consequently, this study aimed to inform mothers whose babies were in the newborn intensive units about breast milk banking and to contribute to the literature about the subject, given the importance of breast milk for neonates in the newborn intensive care units.

\section{MATERIALS AND METHODS}

This descriptive research was performed to observe and collect information about knowledge and attitudes regarding breast milk banking among mothers whose neonates were in the newborn intensive care units of a public hospital in Ankara, the capital city of Turkey, from June to August 2016. The researchers included a short and standard information note that was prepared based on the information in the literature about breast milk banks on the header of the data collection form; this note provided information regarding the fact that there were no breast milk banks in Turkey and limited research has been conducted on the subject. Within this scope, information about where the first breast milk bank was established; the qualifications of donor milk; as well as the analysis, pasteurization, and storage conditions of donor milk were included. Following this, the form consisted of 32 questions that aimed to determine the mothers' observations regarding breast milk banks and the personal characteristics of their babies; the survey was conducted using face-to-face interviews. Study participation was purely voluntary for the mothers. The study was conducted on 102 mothers who willingly provided their written and oral consent for study participation and whose babies were in the incentive care unit during the research period.

\section{Main Points:}

- Breast milk banking has great importance for mothers whose babies are in intensive care and do not have milk secretion.

- In spite of fact that there is no milk banks in Turkey, it is determined that the majority of mothers support the milk bank.

- It has been established that there is a significant relationship between "Request to Benefit from Breast Milk Banking" and mother's educational background, working status, and the place where the mothers spent most of their lives.

- In addition, it has been found that there is significant relationship between "Request to Donate Breast Milk to the Breast Milk Banks" and mother's breast-feeding experience, the institution from which they had received care before the delivery and the place where the mothers spent most of their lives.

\section{Statistical Analysis}

Statistical analysis was performed using the Statistical Package for the Social Sciences software version I7.0 (SPSS Inc., Chicago, IL, USA). Frequency tables and descriptive statistics were used for data analyses. $\chi 2$-cross tab was created according to the expected value levels to examine the relationship between two quantitative variables.

\section{Research questions}

I. What are the views of mothers whose babies are hospitalized in the neonatal intensive care unit about breast milk banking?

2. Do mothers want to take advantage of the milk bank in the newborn intensive care unit?

\section{Ethical Aspect of Research}

Before initiating data collection, written ethical approval was obtained from the Ethics Board of the hospital (23 May 2016; 2016-054). At each step of the research, the principles of "the Declaration of Helsinki" were followed.

\section{RESULTS}

In Table I, some descriptive characteristics of the mothers are shown. Their average age was $28.34 \pm 6.45 \mathrm{y}$, and $44.1 \%$ of the mothers were $26-33$ y old. Total $51 \%$ of all mothers had graduated primary school; $81.4 \%$ were housewives; for $67.6 \%$, their income was equivalent to their expenses; and $87.3 \%$ belonged to elementary families. Total $56.9 \%$ of the newborns were male infants, and $74.5 \%$ were term infants. Further, 38.2\% of the newborns are fed only breast milk, while $56.9 \%$ were fed supplementary formula along with breast milk. Although not included in the table, $56.9 \%$ of the mothers had a vaginal birth, $42.2 \%$ had been pregnant at least 3 , and $39.2 \%$ had given birth twice. Total $41.2 \%$ of the mothers had 2 living children, and $79.4 \%$ of them did not have any previous experience of breast-feeding.

Table 2 shows the data on the mothers' information and observations regarding breast milk banks. Total $95.1 \%$ of the mothers had never heard about the breast milk banks before, and $77.5 \%$ supported the establishment of breast milk banks in Turkey. The most common reason for not supporting the establishment of breast milk banks was that pertaining to religious beliefs (73.9\%). We found that $50 \%$ of the mothers asked to be benefited from the services provided by breast milk banks when needed, and $64.7 \%$ said that they could donate their breast milk if there was a breast milk bank in Turkey. The reason stated by $50 \%$ of the mothers who were willing to donate was the provision of breast milk for infants whose mothers could not provide it. In contrast, $36.1 \%$ of those who were unwilling to donate did so because they believed that they only produced enough milk for their own child. While $55 \%$ of the mothers stated that they did not want to benefit from the breast milk bank even if they needed, $56.9 \%$ of them believed that there would be a demand for breast milk banks in Turkey.

The distribution of mothers who wanted and did not want to avail the services of breast milk banks when needed are shown in Table 3, according to their some characteristics. There was no significant difference in the age, monthly income, and family type of mothers who request to benefit from breast milk bank- 
ing ( $p>0.05$ ). However, there was a significance difference between those who requested to be benefited from breast milk banking in terms of the educational background, working status, and the place where they spent most of their life $(p<0.05)$. Mothers who were educated up to high school level or lower had similar attitudes toward breast milk banking; however, the attitudes of those who were postgraduates were different. Housewives were more reluctant to benefit from breast milk banking than those who had jobs. The place where the mother had spent most of her life influenced the willingness to benefit from breast milk banking; a difference was observed in those who had lived in city centers for a long time.

Table 4 shows the distribution of the characteristics of mothers who were and were not willing to donate breast milk. There

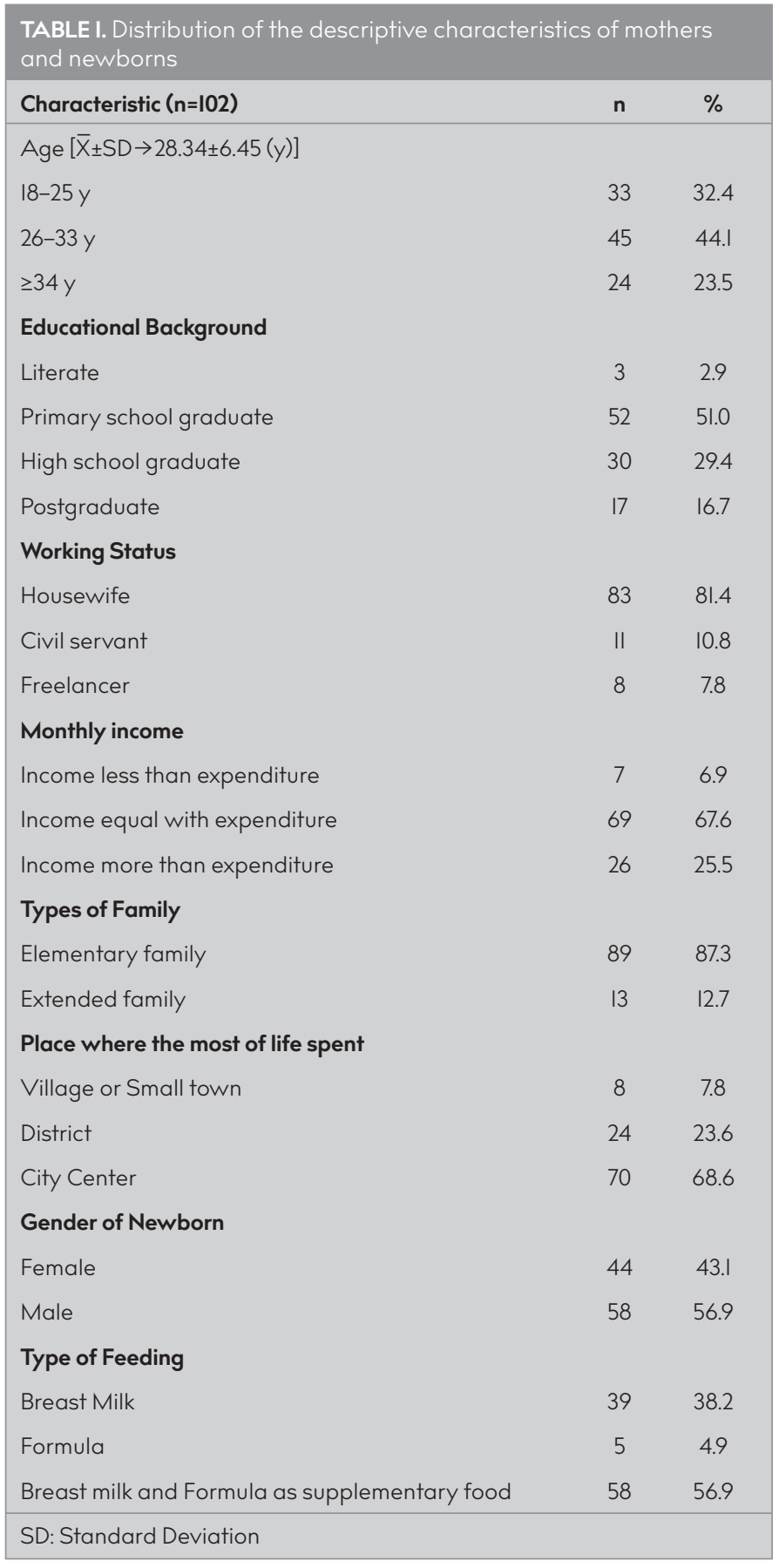

was a significant difference based on the place where they had spent most of their life, breastfeeding experience, and the place where they received care before delivery $(p<0.05)$. It has been established that the place where they spent most of their life influenced their willingness to donate breast milk, and this difference arose from living in the city centers for a long time. More mothers who had no experience about breast-feeding were willing to donate their milk than the ones with experience. Most mothers who were willing to donate their milk had received care from the public hospitals before delivery.

Table 5 shows the distribution of the characteristics of mothers with respect to their information about breast milk bank. There was no significant difference between mothers who did and did not have

TABLE 2. Distribution of the mothers' information and observations regarding breast milk banks

Characteristics $(\mathrm{n}=\mathrm{I02})$

$\mathbf{n}$

$\%$

Heard before about breast milk bank

Heard

$5 \quad 4.9$

Not heard

97

Giving support to breast milk bank in Turkey

Supporter

79

77.5

Not supporter

23

Reasons not giving support to breast milk bank in Turkey $(n=23)$

Religious reasons

$17 \quad 73.9$

Unreliability on records

$4 \quad 17.4$

Unknown grantor

Request to benefit from the milk bank when needed

Requestor

Non-requestor

Willing to donate breast milk if available in Turkey

Willing

Unwilling

Donate reason $(n: 66)$

To give milk to infants whose mothers cannot

To provide that all infants be fed by breast milk

Having extra breast milk

725.8

16

Reason for unwilling to donate breast milk ( $n: 36)$

In the belief that her breast milk is enough only for her own baby

Her spouse will not allow

Cannot find time since she will be giving care

to her own baby

Religious reasons

Request to benefit from breast milk bank when needed

Requestor

Non-Requestor 55.9

Mothers who think that there will be demand to breast milk bank in Turkey

Yes

No 44 
information about breast milk banking in terms of willingness to donate, requesting for milk from breast milk banks when needed, and willingness to benefit from the breast milk bank ( $p>0.05)$.

\section{DISCUSSION}

Breast milk is crucial for at-risk infants in the newborn intensive care units as well as infants and newborns because of its high nutrition content. Therefore, it is recommended that for infants, feeding should be started with their own mothers' milk. If this is unavailable, they should be fed donor milk; formula feeding should be the last resort $(\mathrm{I}, 3)$. Few studies have assessed the awareness and information of mothers and health care personnel about breast milk banking $(2,9,10,11)$. To our knowledge, no study has been conducted on mothers whose children are in the newborn intensive care units.

In our study, although most mothers (95.1\%) stated that they had no information about breast milk banking, they were able to provide some information about breast milk banking, showing a positive attitude. Similarly, a significant number of women had never heard about breast milk banking $(10,12)$. However, Ekșioğlu and her colleagues reported that a high percentage of mothers had information about breast milk banking (2); this result is believed to be attributable to the fact that there was ongoing work for the establishment of breast milk banks in the city where this study was conducted. In our study, $3 / 4$ of the women support the establishment of breast milk banks. Although there is considerable evidence in favor of the benefits of breast milk banking, religious reasons are the most commonly cited cause for unwillingness to support breast milk banking in Turkey. In Islam, sharing of breast milk is considered virtuous; however, it is believed that children who share the breast milk of the same mother become siblings although they are not related by blood $(13,14,15)$ and thus cannot marry each other. Despite these beliefs, at least $50 \%$ of the women have a positive attitude toward the benefits of breast milk banking and $>50 \%$ may donate and receive donor milk from the breast milk bank.

It is noteworthy that $77.5 \%$ of the mothers whose children were in the newborn intensive care unit supported breast milk banking in Turkey; however, overall, 50\% women do and 50\% do not support breast milk banking. According to the study (2) by Ekșioğlu and his colleagues, most mothers (71.3\%) request the establishment of breast milk banks; however, only $52.5 \%$ reported that they would request donor milk when needed. Mackenzie et al. (I0) state that breast milk is the most important source of nutrition for infants and should be preferred over formulas; they support breast milk banking. However, we found that while most mothers were willing to donate their milk, the number of mothers who wanted to receive donor milk when needed was low. In a similar manner, studies $(2,12)$ have shown that the number of mothers who are willing to donate is higher than that of those willing to use donor milk from these banks. Thus, we conclude that mothers are unwilling to feed their children donor milk owing to religious reasons; however, they are willing to help other infants who need breast milk and are unable to receive it from their own mother.

TABLE 3. Distribution of the characteristics of mothers who did and did not request to be benefited from the services of the breast milk banks

\begin{tabular}{|c|c|c|c|}
\hline \multirow[b]{2}{*}{ Characteristics ( $n=102)$} & \multicolumn{2}{|c|}{ Request to benefit from breast milk bank } & \multirow[b]{2}{*}{ Statistical analyses ${ }^{a}$ Possibility } \\
\hline & Requestors $(n=5 I)$ & Non-requestors $(n=5 I)$ & \\
\hline \multicolumn{4}{|l|}{ Age } \\
\hline $26-33 y$ & $26(51.0 \%)$ & $19(37.3 \%)$ & $p=0.156$ \\
\hline$\geq 34 y$ & $13(25.5 \%)$ & II (21.5\%) & \\
\hline \multicolumn{4}{|l|}{ Educational background } \\
\hline Primary school graduate and lower & $23(45.1 \%)$ & $32(62.7 \%)$ & $\chi^{2}=11.947$ \\
\hline High school graduate & $13(25.5 \%)$ & $17(33.4 \%)$ & $p=0.003$ \\
\hline Postgraduate & $15(29.4 \%)$ & $2(3.9 \%)$ & \\
\hline \multicolumn{4}{|l|}{ Working status } \\
\hline Income lower than or equal to expenditure & $35(68.6 \%)$ & $4 \mathrm{l}(80.4 \%)$ & $\chi 2=1.858$ \\
\hline Income more than expenditure & $16(31.4 \%)$ & $10(19.6 \%)$ & $p=0.173$ \\
\hline \multicolumn{4}{|l|}{ Type of family } \\
\hline Elementary family & $44(86.3 \%)$ & $45(88.2 \%)$ & $\chi 2=0.088$ \\
\hline Expended family & $7(\mid 3.7 \%)$ & $6(11.8 \%)$ & $p=0.767$ \\
\hline \multicolumn{4}{|l|}{ Place where the most of life spent } \\
\hline Village or small town or district & $23(45.1 \%)$ & $9(17.6 \%)$ & $\chi 2=8.925$ \\
\hline City center & $28(54.9 \%)$ & $42(82.4 \%)$ & $p=0.003$ \\
\hline
\end{tabular}


TABLE 4. Distribution of the characteristics of mothers who were and were not willing to donate their breast milk to the breast milk bank

\section{Characteristics $(n=102)$}

Educational background

Primary school graduate and lower

High school graduate

Postgraduate

Working status

Housewife

Civil servant/freelancer

\section{Monthly income}

Income lower than or equal to expenditure

Income more than expenditure

\section{Type of family}

Elementary family

Expended family

\section{Place where most of life spent}

Village/small town or district

City center

\section{Breast-feeding experience}

Have experience

No experience

\section{Care before giving birth}

Primary care center

Public hospital

Private hospital

\section{Delivery method}

Vaginal delivery

Cesarean Section

\begin{abstract}
Cesarean Section
\end{abstract}
$28(42.4 \%)$

$47(71.2 \%)$

$19(28.8 \%)$

$26(39.4 \%)$

$34(51.5 \%)$

\section{Willing to donate}

Willing $(n=66) \quad$ Unwilling $(n=36)$

$22(61.1 \%)$

II $(30.6 \%)$

$3(8.3 \%)$

$30(83.3 \%)$

$6(16.7 \%)$

5 I (77.3\%)

25 (69.4\%)

II (30.6\%)

$56(84.8 \%)$

$33(91.7 \%)$

$3(8.3 \%)$

$6(9.1 \%)$

$39(59.1 \%)$

$27(40.9 \%)$
$4(11.1 \%)$

$32(88.9 \%)$

$34(94.4 \%)$

$2(5.6 \%)$

$28(77.8 \%)$

$8(22.2 \%)$

$19(52.8 \%)$

$17(47.2 \%)$ $\chi 2=0.012$

$\mathrm{p}=0.913$

$\chi 2=0.396$

$\mathrm{p}=0.529$

$\chi 2=1.033$

$\mathrm{p}=0.309$

$\chi 2=2.876$

$\mathrm{p}=0.237$

$\chi 2=9.204$

$\mathrm{p}=0.002$

$\chi 2=9.044$

$\mathrm{p}=0.005$

$\chi^{2}=14.610$

$\mathrm{p}=0.001$

$\chi^{2}=0.165$

$\mathrm{p}=0.685$

examine the relationship between two quantitative variables.

TABLE 5. Distribution of the characteristics of mothers who did and did not have information about breast milk banking

\begin{tabular}{|c|c|c|c|}
\hline \multirow[b]{2}{*}{ Characteristics $(n=102)$} & \multicolumn{2}{|c|}{ Having information } & \multirow[b]{2}{*}{ Statistical analyses ${ }^{a}$ Possibility } \\
\hline & Have $(n=5)$ & Not have $(n=97)$ & \\
\hline \multicolumn{4}{|c|}{ Request for breast milk bank } \\
\hline Non-requestor & - & $23(23.7 \%)$ & $p=0.216$ \\
\hline \multicolumn{4}{|l|}{ Willingness to donate } \\
\hline Unwilling & - & $36(37.1 \%)$ & $p=0.090$ \\
\hline \multicolumn{4}{|c|}{ Request for milk from breast milk bank when needed } \\
\hline Requestor & $3(60.0 \%)$ & $42(43.3 \%)$ & $\chi 2=0.538$ \\
\hline Non-requestor & $2(40.0 \%)$ & $55(56.7 \%)$ & $p=0.463$ \\
\hline \multicolumn{4}{|c|}{ Request to benefit from breast milk bank } \\
\hline
\end{tabular}


In our study, the most common reason for mothers to not support the establishment of breast milk banks was pertaining to religious beliefs. In contrast, other studies (10, 16-18) have cited reasons other than religious beliefs for this attitude among mothers. Helping each other and meeting the others' legitimate needs are among the fundamental principles of Islam, and this requires giving permission for breast milk banks (I3).

It has been established that the mothers who live in city centers who do not have breastfeeding experience before and who received care from public hospitals before delivery have more positive attitudes toward breast milk banking. Thus, the mother's attitudes regarding this issue are closely associated to their social status and easy accessibility to sources such as health facilities and breastfeeding oriented foundations.

The study was conducted at a single hospital, and some mothers refused to participate in the study. These can be considered the limitations of this study.

Consequently, although most mothers supported the establishment of breast milk banks in Turkey, about $50 \%$ were unwilling to donate or benefit from the services for certain reasons. Considering the fact that the next-best nutrition source for atrisk children after their own mother's milk is donor breast milk, awareness and responsibilities of nurses are crucial in the popularization of breast milk donation because nurses are health care personnel responsible for the protection and developing the health of the infant and mother. Thus, if nurses, especially those working in postpartum clinics and newborn intensive care units give information to parents about breast milk banks, breast milk donation, and the benefits of donor milk, traditional believes and attitudes may change, and concerns about the safety and nutrition of donor milk would be reduced.

\section{Study Limitations}

The research was conducted in a single center. Therefore, it was limited to mothers who met the sampling criteria and agreed to participate in the study. Therefore, the research results can be generalized only to this group.

Based on studies about the breast milk banking, mothers can be informed about the subject, and the demand for breast milk banks can be increased to overcome the obstacles in the establishment of breast milk banks. In addition to all above-mentioned explanations, it is recommended that health care personnel be informed about the breast milk banking and that the mothers be informed about the issue in a fair and impartial manner.

Ethics Committee Approval: Ethics committee approval was received for this study from the Ethics Board of Ankara Paediatrics Haematology-Oncology Training and Research Hospital (23 May 20l6; 20l6-054).

Informed Consent: Written informed consent was obtained from patients who participated in this study.

Peer-review: Externally peer-reviewed.

Author contributions: Concept - R.G., A.Ș.E.; Design - R.G., A.Ș.E.; Supervision - A.Ș.E.; Resource: - R.G., A.Ș.E.; Material - R.G., A.S.E.; Data Collection and/or Processing - R.G.; Analysis and/or Interpretation - R.G.,
A.S.E.; Literature Search - R.G., A.S.E.; Writing - R.G., A.S.E.; Critical Reviews - R.G., A.Ș.E.

Acknowledgements: The corresponding author would like to thank to Mr. Bayram Gürel for his valuable writing assistance.

Conflict of Interest: The authors have no conflicts of interest to declare.

Financial Disclosure: The authors declared that this study has received no financial support.

\section{REFERENCES}

I. American Academy of Pediatrics. Policy Statement: Breastfeeding and the use of human milk. Pediatrics 2012. p. e827.[CrossRef]

2. Ekșioğlu A, Yeșil Y, Turfan EC . Annelerin süt bankası hakkındaki görüșleri: İzmir örneği. Turk Pediatri Ars 2015; 50(2): 83-9. [CrossRef]

3. World Health Organization [Internet].France: Infant and young child feeding. Model Chapter for textbooks for medical students and allied health professionals; (cited $2016 \mathrm{Dec}$ 31) Available from: URL: https://apps.who.int/iris/bitstream/ handle/10665/44II7/978924I597494_eng.pdf;isessionid=B3IC753C5C7C02C055553BIBDA963B57? sequence=1

4. Unicef [Internet]. New York: Breastfeeding: foundation for a healthy future; (cited 2018 Jan 5.) Available from: URL: https: //www.unicef. org/publications/files/pub_brochure_en.pdf

5. Sullivan S, Schanler RJ, Kim JH, Patel AL, Trawöger R, Kiechl-Kohlendorfer $\mathrm{U}$, et al. An exclusively human milk-based diet is associated with a lower rate of necrotizing enterocolitis than a diet of human milk and bovine milk-based products. J Pediatr 2010; 156(4): 562-7. [CrossRef]

6. Quigley MA, McGuire W. Formula milk versus donor breast milk for feeding preterm or low birth weight infants (Rewiev). Cochrane Database Syst Rev 2014; (4): CD00297I. [CrossRef]

7. Demirtaș B. Türkiye'de anne sütü bankaları olmalı mı? Anadolu Hemșirelik ve Sağlık Bilimleri Dergisi 20ll;14(I): 73-7.

8. Büyükcan T. Anne sütü bankacılığı ve çeșitli ülke uygulamaları. Türkiye Büyük Millet Meclisi Aylık Bülteni 20I3; 189: 28-30.

9. Șentürk Erenel A, Ünal Toprak F, Gölbașı Z, Pelit Aksu S, Arslan Gürcüoğlu E, Uçar T, et al. Sağlık personelinin anne sütü bankalarına ilișkin bilgi ve görüșlerinin belirlenmesine yönelik çok merkezli bir çalıșma. GMJ 2017; 28(2): 107-I. [CrossRef]

10. Mackenzie C, Javanparast S, Newman L. Mothers' knowledge of and attitudes toward human milk banking in South Australia: a qualitative study. J Hum Lact 2013; 29(2): 222-9. [CrossRef]

II. Simmer K, Hartmann B. The knowns and unknowns of human milk banking. Early Hum Dev 2009; 85(II): 70I-4. [CrossRef]

12. Görol A, Özkan H, Celebi A. Turkish women's knowledge and views regarding mother's milk banking. Collegian 20I4; 2I(3): 239-44. [CrossRef]

13. Pekdemir Ș. İslam hukukuna göre anne sütü bankaları. JASSS 2015; 40: 537-54. [CrossRef]

14. Spatz DL, Robinson AC, Froh EB. Cost and Use of Pasteurized Donor Human Milk at a Children's Hospital. J Obstet Gynecol Neonatal Nurs 2018; 47(4): 583-88. [CrossRef]

15. Ramli N, Ibrahim NR, Hans VR. Human milk banks: The benefits and issues in an Islamic setting. Eastern J Med 2010; 15(4): 163-7.

16. Coutsoudis I, Petrites A, Coutsoudis A. Acceptability of donated breast milk in a resource limited South African setting. Int Breastfeed J 20II; 6(3): I-I0. [CrossRef]

17. Gribble KD, Hausman BL. Milk sharing and formula feeding: Infant feeding risks in comparative perspective? Australas Med J 2012; 5(5): 275-83. [CrossRef]

18. Thomaz ACP, Loureiro LVM, Oliveira TS, Furtado Montenegro NC, Dantas Almeida Júnior E, Fernando Rodrigues Soriano C, et al. The human milk donation experience: motives, influencing factors, and regular donation. J Hum Lac 2008; 24(I): 69-76. [CrossRef] 